\title{
The Effect of Blood Glucose Value on the Short-term Mortality of Acute Ischemic Stroke
}

\author{
(1) Osman Serhat Tokgöz ${ }^{1}$, (1) Feridun Karakurt ${ }^{2}$, (1) Ahmet Buğrul ${ }^{1}$
}

1Department of Neurology, Necmettin Erbakan University Meram Medical Faculty, Konya, Turkey

2Department of Endocrinology, Necmettin Erbakan University Meram Medical Faculty, Konya, Turkey

\begin{abstract}
Aim: This study aimed to examine the relationship between short-term mortality and blood glucose values (BGV) obtained during the first week of ischemic stroke, when neurological causes, such as increased intracranial pressure, are mainly predominant in mortality prediction.

Materials and Methods: This is a retrospective study that includes 417 patients with acute ischemic stroke (AIS), who were admitted to our hospital within the first 24 hours of the stroke. Data were recorded using the International Classification of Diseases Code. On the first, third, fifth, and seventh days of the stroke, the effect of BGV on the patient's functional outcome was evaluated.

Results: Of 417 patients, 90 (21.58\%) died within a one-month follow-up period. There was no difference between the mortality and survival groups in terms of diabetes mellitus (DM) history $(\chi 2=0.783 ; p=0.224)$. On the first, third, fifth, and seventh day of the stroke, BGV were significantly higher in the mortality group $(130.5 \mathrm{mg} / \mathrm{dL}, 124.5 \mathrm{mg} / \mathrm{dL}, 133.5 \mathrm{mg} / \mathrm{dL}$, and $132.5 \mathrm{mg} / \mathrm{dL}$, respectively, according to the receiver operating characteristic analysis) than in the survival group $(\mathrm{p}<0.05)$. BGV of the fifth day $(133.5 \mathrm{mg} / \mathrm{dL})$ was an independent predictor for mortality (hazard ratio: 3.001; 95\% confidence interval (1.43-6.3); $p=0.004)$, while BGV of the other days were dependent on a coma scale.

Conclusion: Hyperglycemia predicting short-term AIS mortality might be a DM-independent stress hyperglycemia. Although hyperglycemia is predominantly a coma-scale-dependent [modified Rankin Scale (mRS)] predictor during the first week of blood glucose monitoring, BGV of the fifth day may be an independent predictor of short-term mortality.
\end{abstract}

Keywords: Glucose, stroke, mortality, outcome

\section{Introduction}

Cerebrovascular disease is a clinical syndrome characterized by sudden onset of focal or generalized loss of cerebral function, and lasting more than 24 hours or resulting in death, which is due to vascular causes. It takes the first place among morbidity causes and the second place among mortality causes. Mortality rate in cerebrovascular disease is about 20\% (1). Atherosclerosis, the most important cause of ischemic stroke, is a chronic inflammatory process. For preventing or reversing this process, treatments of risk factors such as hypertension, diabetes mellitus (DM), coronary artery disease (CAD), smoking, and obesity have been included in the guidelines. The prevalence of stroke is 500-600/100,000 in Caucasian populations (1). Currently, there are many clinical studies aiming to decrease the frequency, mortality and morbidity of stroke by controlling these risk factors.

DM increases the risk of stroke by 2-6 times (2-5) and DM is responsible for $5 \%$ of all strokes (6). Therefore, blood glucose value (BGV) control is very important to protect the patient from stroke. Despite all these primary protection efforts, stroke incidence is 1-2/1,000 (1). Acute ischemic stroke (AIS) period is a different period from chronic vascular atherosclerotic inflammatory processes. Ischemic neuron deaths and liquefaction necrosis accompanied by an inflammatory process develop within minutes depending on the size and location of the occluded vessel in the brain tissue, which is very sensitive to ischemia. Metabolic 
stress caused by extensive clinical findings, ranging from mild hemiparesis to deep coma, suggests that we need to be more careful in controlling the primary risk factors during this period. There is conflicting information in literature regarding these effects of BGV control and DM history on the mortality and morbidity in acute-term ischemic stroke (7).

The aim of this study is to examine the relationship BGVs of first week with short-term mortality in patients with acute ischemic stroke.

\section{Materials and Methods}

This is a hospital-based retrospective study. Four hundred and seventeen patients with AIS were screened between 2010 and 2015. Patients admitted within the first 24 hours of stroke were included in the study. Exclusion criteria were given in the flow chart (Figure 1).

\section{Study protocol}

All patients were screened using the International Classification of diseases, $10^{\text {th }}$ revision code "G46.0-2" from the database of the hospital's electronic record system. Four hundred and seventeen patients met the criteria. Clinical and demographic characteristics of the patient were obtained from the archive records of the patient. Glasgow coma scores (GCS) and the modified Rankin scores (mRS) were recorded. BGVs on the $1^{\text {st }}, 3^{\text {rd }}, 5^{\text {th }}$ and $7^{\text {th }}$ days were determined from biochemistry records. GCS is between 3-15 points (15, normal: 3 , worst), mRS is between $0-5$ (0, normal: 5 , worst). The hospital mortalities of the patients were obtained from the medical records. Patients, who were discharged from the hospital before 30 days, were determined from the outpatient clinic records or contacted by the telephone.

\section{Statistical Analysis}

Data were analyzed using SPSS software (version 15.0;SPSS Inc, Chicago, IL) and presented as mean ( \pm ) standard deviation or median (95\% confidence interval). "Kolmogorov-Smirnov test" was used as normality test. "Student t-test" was used for parametric comparisons between the two groups, and "Mann-Whitney U test" for nonparametric comparisons. $\chi^{2}$ test was used for comparison of categorical data. Receiver operating characteristic (ROC) analysis was used to define areas the areas under the curve (AUC), sensitivity, and specificity,

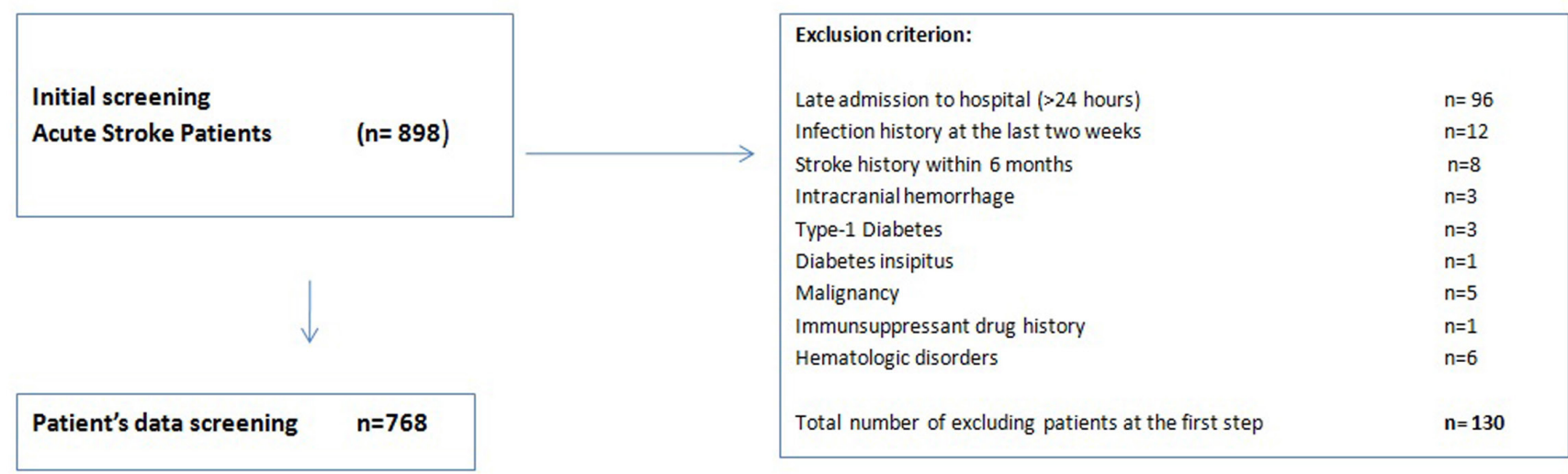

Insufficient medical records $n=351$

417

Ischemic Stroke

Cardioembolic

Small-vessel occlusion

Atherosclerotic large-vessel disease [stenosis of over $50 \%$ or atherosclerotic plaque]

Other determined etiology

Lupus anticoagulant, Antiphospholipid antibodies, Protein C or S deficiency

Collagen tissue diseases

Hyperviscosity syndromes

Arterial dissection,

Undetermined Etiology

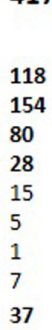

Figure 1. Flow chart of the study 
positive and negative predictive values. "Kaplan-Meier" survival analysis was performed according to ROC estimation of BGVs. Cox regression analysis was performed to determine independent predictive risk factors for mortality. For the mortality analysis, two models were used to observe whether or not the coma score (mRS) effects on the variables. Model 1 includes coma scale (mRS), glucose and risk factors such as hypertension, DM, CAD, triglyceride, while model 2 includes only glucose and risk factors (hypertension, DM, CAD, and triglyceride). $\mathrm{P}<0.05$ was considered statistically significant.

\section{Results}

Four hundred and seventeen patients with a mean age of $67.39 \pm 13.0$ were included in the study. The demographic and clinical characteristics of the patients are shown in Table 1. The mortality rate during the 30-day follow-up was $21.58(n=90)$. BGVs and $\mathrm{HbA1C}$ values are shown in Table 1 on the $1^{\text {st }}, 3^{\text {rd }}, 5^{\text {th }}$ and $7^{\text {th }}$ days of admission. Age, stroke history, hypertension, CAD were significantly higher in the mortality group. The mRS and the white cell count taken at admission, and the $1^{\text {st }}, 3^{\text {rd }}$, $5^{\text {th }}$ and $7^{\text {th }}$ day BGVs were significantly higher in the mortality group, whereas $\mathrm{HbA1C}$, triglyceride and hemoglobin values were significantly lower. Although hemoglobin and $\mathrm{HbA1c}$ values were significantly lower in the mortality group, these two parameters were neglected in further analyzes because the values were very close to each other and were within normal range (Table 1). Since there was no significant difference between the mortality and survival groups in terms of DM history $\left(\chi^{2}=0.783, p: 0.224\right) .45 .3 \%$ $(n=199)$ of all patients had hyperglycemia $(>7 \mathrm{mmol})$ on the first day-blood glucose measurements [23.5\% $(n=103)$ with DM history and the remaining $21.8 \%(n=96)$ without DM history].

In ROC analysis of these $1^{\text {st }}, 3^{\text {rd }}, 5^{\text {th }}$ and $7^{\text {th }}$ day BGV's, blood glucose predictive values for mortality were 130.5 (AUC: 0.612); 124.5 (AUC: 0.618); 133.5 (AUC-B1: 0.630); $132.5 \mathrm{mg} / \mathrm{dL}$ (AUC: 0.652), respectively (Figure 2). Kaplan-Meier survival curves according to the $1^{\text {st }}$ and $5^{\text {th }}$ day predictive values are presented in Figure 3. It was found that the $5^{\text {th }}$ and $7^{\text {th }}$ BGVs below the threshold value were more sensitive and specificity than the others in the predicting of mortality, and cox regression models were applied. In the Model-1 analysis including mRS in the Cox regression analysis, the $5^{\text {th }}$ day BGVs was an independent predictor, but the others (the $1^{\text {st }}, 3^{\text {rd }}$ and $7^{\text {th }}$ days) were not. In the Model-2 analysis without $\mathrm{mRS}$, the high BGVs according to their predictive value at all times were independent predictors of mortality (Table 2, 3). In addition, CAD and low triglyceride value were independent predictors of mortality.

\section{Discussion}

The DM history in stroke patients is about $10-20 \%$, and hyperglycemia has been reported in $5-32 \%$ of patients with no history of DM in post-stroke hyperglycemia (8-10), which is similar to our results. $45.3 \%$ of all patients had high blood glucose concentration (23.5\% of them were previously diabetics and the remaining $21.8 \%$ nondiabetics) in our study.

The mechanism of the increased glucose concentration in AIS is not fully understood. The first hypothesis is glucose intolerance or undiagnosed DM, the second is due to neurological diseases, and the third is to respond to the increased stress $(8,11)$. In addition, Rosso et al. (12) emphasized that hyperglycemia worsened the transformation of the penumbral area into the infarct.

The literature and our results pointed out that type-2-DM has no effect on the severity of ischemic stroke $(8,11,13-15)$. Stead et al. (16) also reported that hyperglycemia leads to clinical deterioration in AIS, which is worse in non-diabetic patients than in diabetics. O'Neill et al. (11) reported that hyperglycemia is a predictor of poor prognosis as a result of multiple samples taken on days 1, 3, 7, 14, 30 and 90. In the Second European Cooperative Acute Stroke Study (ECASS-II), BGVs above 140 mg/dL in nondiabetic patients within 24 hours after stroke was reported to be an independent predictor of 90-day poor functional outcome (17).

Despite the above literature, some reports suggest that stress hyperglycemia is not effective on the functional outcome of AIS, and it is suggested that the related studies do not include clinical severity in the analysis $(7,18,19)$. Szczudlik et al. (8) reported that one-year periodic follow-up of hyperglycemia was not an independent predictor of 1-year mortality.

Prognosis studies are mostly examined the single BGVs at admission. There are a few studies in the literature regarding to periodic glucose follow-up $(8,11)$, but the predictive value of BGV in the AIS short-term mortality is not clear yet in literature. The reason of speculative results may be that the acute stroke period, especially first a week, has not been examined in detail. Neurological problems are at the forefront among the causes of mortality in the first week. The most important mortality reason in this period is the increased intracranial pressure caused by severe brain edema. The maximum brain edema period is the first 3-5 days, and then clinic outcome gradually improves, because intracranial pressure gradually decreases. Therefore, the first week blood glucose monitoring was performed in patients with AIS in the study, and it was suggested that the $5^{\text {th }}$ and day $7^{\text {th }}$ day values might be more valuable for mortality. In particular, 


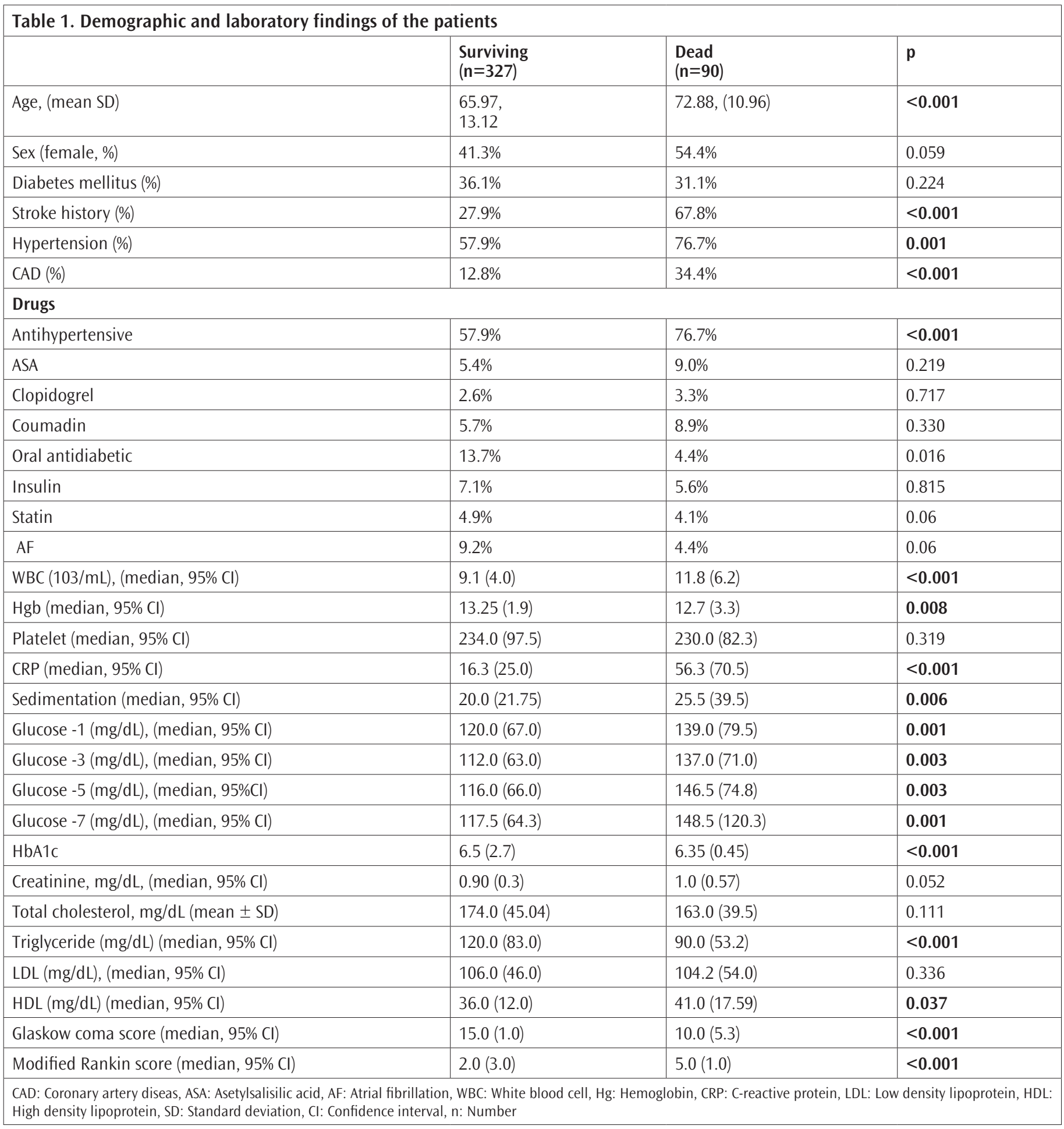

the $5^{\text {th }}$ day BGV $(133.5 \mathrm{mg} / \mathrm{dL})$ was found to be an independent predictor of mortality, which may be due to the period in which brain edema gradually decreases or co-incidence. The other $1^{\text {st }}$ $, 3^{\text {rd }}, 7^{\text {th }}$ day BGV'es were dependent to coma score (mRS) (Table 2,3). Kılıc et al. (20) also examined temporal hyperglycemia on the prognosis of AIS in Anatolian region, but they examined the single BGV at admission on the AIS outcome, and their study hasn't got multivariate analysis. They suggested that hyperglycemia had a negative effect on AIS.

The European stroke organization guideline stressed the need to adjust blood glucose concentrations above $10 \mathrm{mmol}(180 \mathrm{mg} /$ $\mathrm{dL}$ ) by titrating with insulin (21). The American stroke association guideline emphasized the necessity of insulin treatment when it exceeded 140-185 mg/dL (American Society of Anesthesiologists). 
The Shine study suggested the need for a target blood glucose concentration of $80-130 \mathrm{mg} / \mathrm{dL}$ (22). For blood glucose upper limit, Capes et al. (18) declared $126 \mathrm{mg} / \mathrm{dL}$ in their meta-analysis, and Ntaios et al. (23) reported an upper limit of $7.3 \mathrm{mmol}(131.4$ $\mathrm{mg} / \mathrm{dL}$ ), which are consistent with our results. In our study, a threshold value of blood glucose is about $130 \mathrm{mg} / \mathrm{dL}$ for mortality in acute ischemic stroke patients.
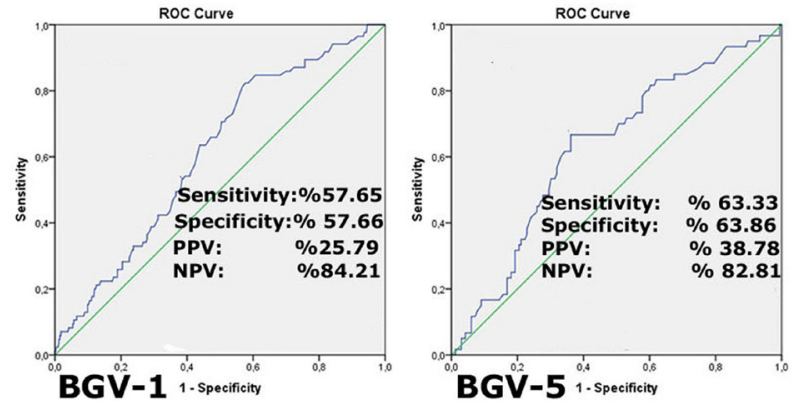

Figure 2. $1^{\text {st }}$ and $5^{\text {th }}$ days blood BGVs in the ROC analysis BGV: Blood glucose value, ROC: Receiver operating characteristic

\section{Study Limitations}

Metabolic stress markers such as catecholamine and steroid values, the effect of insulin, body mass indexes are not recorded. The study had to exclude so many patients (about $40 \%$ of the cases) due to not enough information. A single-center study is also among the limitations of our study.
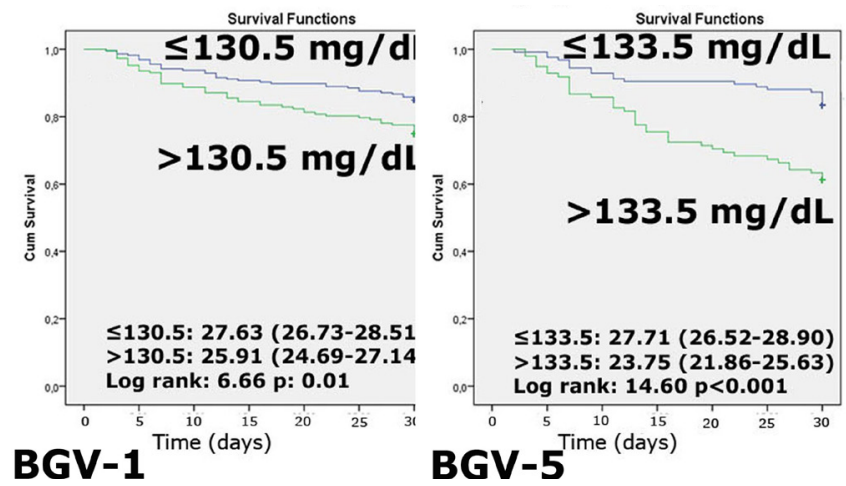

Figure 3. Kaplan-Meier survival curves according to the $1^{\text {st }}$ and $5^{\text {th }}$ day predictive values.

BGV: Blood glucose value

\begin{tabular}{|c|c|c|c|c|}
\hline $1^{\text {st }}$ day & $\begin{array}{l}\text { Model } 1 \\
\text { HR }(95 \% \mathrm{Cl})\end{array}$ & $\mathrm{p}$ & $\begin{array}{l}\text { Model } 2 \\
\text { HR }(95 \% \mathrm{Cl})\end{array}$ & $\mathrm{p}$ \\
\hline HT & $\begin{array}{l}2.160 \\
(1.09-4.27)\end{array}$ & 0.027 & $\begin{array}{l}2.504 \\
(1.26-4.96)\end{array}$ & $0.009 *$ \\
\hline DM & $\begin{array}{l}1.518 \\
(0.76-3.04)\end{array}$ & 0.238 & $\begin{array}{l}1.828 \\
(0.92-3.63)\end{array}$ & 0.084 \\
\hline CAD & $\begin{array}{l}2.868 \\
(1.57-5.24)\end{array}$ & 0.001 & $\begin{array}{l}3.200 \\
(1.77-5.79)\end{array}$ & $<0.0001^{*}$ \\
\hline TG & $\begin{array}{l}0.989 \\
(0.98-0.995)\end{array}$ & 0.001 & $\begin{array}{l}0.986 \\
(0.98-0.995)\end{array}$ & $<0.0001^{*}$ \\
\hline BGV (1): > $130.5 \mathrm{mg} / \mathrm{dL}$ & $\begin{array}{l}1.748 \\
(0.977-3.13)\end{array}$ & 0.060 & $\begin{array}{l}2.189 \\
(1.23-3.91)\end{array}$ & $0.008^{*}$ \\
\hline $\mathrm{mRs}$ & $\begin{array}{l}2.559 \\
(1.84-3.55)\end{array}$ & $<0.0001^{*}$ & - & - \\
\hline $3^{\text {rd day }}$ & $\mathrm{HR}(\mathbf{9} \% \mathrm{Cl})$ & p & HR $(95 \% \mathrm{Cl})$ & p \\
\hline HT & $\begin{array}{l}1.914 \\
(0.89-4.14)\end{array}$ & 0.099 & $\begin{array}{l}2.581 \\
(1.21-5.51)\end{array}$ & $0.014 *$ \\
\hline DM & $\begin{array}{l}1.380 \\
(0.66-2.88)\end{array}$ & 0.390 & $\begin{array}{l}1.776 \\
(0.85-3.71)\end{array}$ & 0.127 \\
\hline CAD & $\begin{array}{l}2.258 \\
(1.13-4.53)\end{array}$ & 0.022 & $\begin{array}{l}2.115 \\
(1.07-4.19)\end{array}$ & $0.032^{*}$ \\
\hline TG & $\begin{array}{l}0.99 \\
(0.98-1)\end{array}$ & 0.005 & $\begin{array}{l}0.989 \\
(0.98-1)\end{array}$ & $0.001^{*}$ \\
\hline BGV (3): > $124.5 \mathrm{mg} / \mathrm{dL}$ & $\begin{array}{l}1.566 \\
(0.81-3.01)\end{array}$ & 0.179 & $\begin{array}{l}2.272 \\
(1.19-4.35)\end{array}$ & $0.013^{*}$ \\
\hline $\mathrm{mRs}$ & $\begin{array}{l}2.473 \\
(1.69-3.62)\end{array}$ & $<0.0001^{*}$ & - & - \\
\hline
\end{tabular}




\begin{tabular}{|c|c|c|c|c|}
\hline $5^{\text {th }}$ day & $\begin{array}{l}\text { Model } 1 \\
\text { HR }(95 \% \mathrm{CI})\end{array}$ & p & $\begin{array}{l}\text { Model } 2 \\
\text { HR }(95 \% \mathrm{CI})\end{array}$ & p \\
\hline HT & $\begin{array}{l}1.662 \\
(0.78-3.53)\end{array}$ & 0.187 & $\begin{array}{l}1.877 \\
(0.88-4.01)\end{array}$ & 0.104 \\
\hline DM & $\begin{array}{l}2.022 \\
(0.93-4.41)\end{array}$ & 0.077 & $\begin{array}{l}2.764 \\
(1.28-5.97)\end{array}$ & $0.010^{*}$ \\
\hline CAD & $\begin{array}{l}2.206 \\
(1.08-4.49)\end{array}$ & 0.029 & $\begin{array}{l}2.475 \\
(1.23-5)\end{array}$ & $0.012^{*}$ \\
\hline TG & $\begin{array}{l}0.987 \\
(0.98-0.995)\end{array}$ & 0.002 & $\begin{array}{l}0.984 \\
(0.98-0.995)\end{array}$ & $0.000^{*}$ \\
\hline BGV (5): >133.5 mg/dL & $\begin{array}{l}3.001 \\
(1.43-6.3)\end{array}$ & $0.004^{*}$ & $\begin{array}{l}4.699 \\
(2.32-9.5)\end{array}$ & $<0.0001^{*}$ \\
\hline $\mathrm{mRs}$ & $\begin{array}{l}1.767 \\
(1.18-2.64)\end{array}$ & 0.006 & - & - \\
\hline $7^{\text {th }}$ day & HR $(95 \% \mathrm{Cl})$ & $\mathbf{p}$ & $\mathrm{HR}(95 \% \mathrm{CI})$ & p \\
\hline HT & $\begin{array}{l}1.613 \\
(0.74-3.5)\end{array}$ & 0.227 & $\begin{array}{l}1.754 \\
(0.8-3.82)\end{array}$ & 0.158 \\
\hline DM & $\begin{array}{l}1.382 \\
(0.62-3.08)\end{array}$ & 0.428 & $\begin{array}{l}1.834 \\
(0.83-4.05)\end{array}$ & 0.134 \\
\hline CAD & $\begin{array}{l}2.607 \\
(1.27-5.34)\end{array}$ & 0.009 & $\begin{array}{l}2.826 \\
(1.41-5.68)\end{array}$ & $0.004^{*}$ \\
\hline TG & $\begin{array}{l}0.99 \\
(0.98-0.995)\end{array}$ & 0.010 & $\begin{array}{l}0.988 \\
(0.98-0.995)\end{array}$ & $0.003 *$ \\
\hline BGV (7): >132.5 mg/dL & $\begin{array}{l}1.854 \\
(0.88-3.89)\end{array}$ & 0.103 & $\begin{array}{l}2.775 \\
(1.36-5.66)\end{array}$ & $0.005^{*}$ \\
\hline mRs & $\begin{array}{l}1.869 \\
(1.24-2.82)\end{array}$ & 0.003 & - & - \\
\hline
\end{tabular}

\section{Conclusion}

This is the short-term outcome study with a first-week-blood glucose monitoring in the acute ischemic stroke. Hyperglycemia without DM history during this period might be related to metabolic stress. Presented results show that patients die has higher glucose levels, but only on the $5^{\text {th }}$ day the level of glucose is an explanatory factor. mRS, is as expected, has during all the period demonstrate higher predictive value. The $5^{\text {th }}$-day- BGVs may be an independent predictor for short-term ischemic stroke mortality, which coincides with the period when brain edema begins to decrease.

\section{Ethics}

Ethics Committee Approval: This study was approved by Necmettin Erbakan University, Meram Faculty of Medicine, Pharmaceuticals and Medical Devices Ethics Committee (decision no: 2019/1942, date: 21.06.2019).

Informed Consent: Retrospective study.
Peer-review: Externally peer-reviewed.

\section{Authorship Contributions}

Surgical and Medical Practices: O.S.T., F.K., A.B., Concept: O.S.T., F.K., Design: O.S.T., F.K., Data Collection or Processing: O.S.T., A.B., Analysis or Interpretation: O.S.T., F.K., Literature Search: O.S.T., F.K., A.B., Writing: O.S.T., F.K.

Conflict of Interest: No conflict of interest was declared by the authors.

Financial Disclosure: The authors declared that this study received no financial support.

\section{References}

1. Öztürk \$̦. Epidemiology of cerebrovascular diseases and Risk factorsperspectives of the world and Turkey. Turk J Geriatr. 2009;13:51-8.

2. Gaillard T, Miller E. Guidelines for Stroke Survivors With Diabetes Mellitus. Stroke. 2018;49:215-7.

3. Zhang Z, Yan J, Shi H. Hyperglycemia as a Risk Factor of Ischemic Stroke. J Drug Metab Toxicol. 2013;4:153. 
4. Emerging Risk Factors Collaboration, Sarwar N, Gao P, Seshasai SR, Gobin $R$, Kaptoge $S$, et al. Diabetes mellitus, fasting blood glucose concentration, and risk of vascular disease: a collaborative meta-analysis of 102 prospective studies. Lancet. 2010;375:2215-22.

5. Luitse MJ, Biessels GJ, Rutten GE, Kappelle LJ. Diabetes, hyperglycaemia, and acute ischaemic stroke. Lancet Neurol. 2012;11:261-71.

6. O’Donnell MJ, Xavier D, Liu L, Zhang H, Chin SL, Rao-Melacini P, et al. Risk factors for ischaemic and intracerebral haemorrhagic stroke in 22 countries (the INTERSTROKE study): a case-control study. Lancet. 2010 ;376:112-23.

7. Tziomalos K, Spanou M, Bouziana SD, Papadopoulou M, Giampatzis V, Kostaki $\mathrm{S}$, et al. Type 2 diabetes is associated with a worse functional outcome of ischemic stroke. World J Diabetes. 2014;5:939-44.

8. Szczudlik A, Slowik A, Turaj W, Wyrwicz-Petkow U, Pera J, Dziedzic T, et al. Transient hyperglycemia in ischemic stroke patients. J Neurol Sci. 2001;189:105-11.

9. Ntaios G, Egli M, Arsovska A, Joye D, Bettex Y, Lauber E, et al. An intravenous insulin protocol for strict glycemic control in acute ischaemic stroke. Eur J Neurol. 2012;19:443-51.

10. Ntaios G, Faouzi M, Ferrari J, Lang W, Vemmos K, Michel P. An integer-based score to predict functional outcome in acute ischemic stroke: the ASTRAL score. Neurology. 2012;78:1916-22.

11. O'Neill PA, Davies I, Fullerton KJ, Bennett D. Stress hormone and blood glucose response following acute stroke in the elderly. Stroke. 1991;22:842-7.

12. Rosso C, Attal Y, Deltour S, Hevia-Montiel N, Lehéricy S, Crozier S, et al. Hyperglycemia and the fate of apparent diffusion coefficient-defined ischemic penumbra. AJNR Am J Neuroradiol. 2011;32:852-6.

13. Jørgensen $\mathrm{H}$, Nakayama $\mathrm{H}$, Raaschou HO, Olsen TS. Stroke in patients with diabetes. The Copenhagen Stroke Study. Stroke. 1994;25:1977-84.

14. Karapanayiotides T, Piechowski-Jozwiak B, van Melle G, Bogousslavsky J, Devuyst G. Stroke patterns, etiology, and prognosis in patients with diabetes mellitus. Neurology. 2004;62:1558-62.
15. Tuttolomondo A, Pinto A, Salemi G, Di Raimondo D, Di Sciacca R, Fernandez $P$, et al. Diabetic and non-diabetic subjects with ischemic stroke: differences, subtype distribution and outcome. Nutr Metab Cardiovasc Dis. 2008;18:1527.

16. Stead LG, Gilmore RM, Bellolio MF, Mishra S, Bhagra A, Vaidyanathan L, et al. Hyperglycemia as an independent predictor of worse outcome in nondiabetic patients presenting with acute ischemic stroke. Neurocrit Care. 2009;10:181-6.

17. Yong M, Kaste M. Dynamic of hyperglycemia as a predictor of stroke outcome in the ECASS-II trial. Stroke. 2008;39:2749-55.

18. Capes SE, Hunt D, Malmberg K, Pathak P, Gerstein HC. Stress hyperglycemia and prognosis of stroke in nondiabetic and diabetic patients: a systematic overview. Stroke. 2001;32:2426-32.

19. Weir CJ, Murray GD, Dyker AG, Lees KR. Is hyperglycaemia an independent predictor of poor outcome after acute stroke? Results of a long-term follow up study. BMJ. 1997;314:1303-6.

20. Kılıc S, Gultekin M, Soyuer F, Unluhizarci K, Soyuer A. The effect of temporary hyperglycemia on the prognosis of stroke in patients with acute ischemic stroke. Turk J Cereb Dis. 2012;8:72-6.

21. Kreisel SH, Berschin UM, Hammes HP, Leweling H, Bertsch T, Hennerici MG, et al. Pragmatic management of hyperglycaemia in acute ischaemic stroke: safety and feasibility of intensive intravenous insulin treatment. Cerebrovasc Dis. 2009;27:167-75.

22. Bruno A, Durkalski VL, Hall CE, Juneja R, Barsan WG, Janis S, et al. The Stroke Hyperglycemia Insulin Network Effort (SHINE) trial protocol: a randomized, blinded, efficacy trial of standard vs. intensive hyperglycemia management in acute stroke. Int J Stroke. 2014;9:246-51.

23. Ntaios G, Papavasileiou V, Bargiota A, Makaritsis K, Michel P. Intravenous insulin treatment in acute stroke: a systematic review and meta-analysis of randomized controlled trials. Int J Stroke. 2014;9:489-93. 